\title{
MERCANTILIZAÇÃO, PROTEÇÃO SOCIAL E EMANCIPAÇÃO: AS AMBIVALÊNCIAS DO FEMINISMO NA CRISE DO CAPITALISMO
}

\author{
Nancy Fraser* \\ MARKETIZATION, SOCIAL PROTECTION AND EMANCIPATION: \\ AMBIVALENCES OF FEMINISM IN THE CAPITALIST CRISIS \\ TRADução Natália Luchini
}

\section{RESUMO}

ESSE CAPÍTULO APRESENTA REFLEXÕES SOBRE AS PERSPECTIVAS DO FEMINISMO NO QUADRO DA CRISE ATUAL DO CAPITALISMO neoliberal. Ele se baseia nas teorias de Karl Polanyi que EXPLICARAM O PROCESSO HISTÓRICO DA CRISE PELO CONFLITO CENTRAL ENTRE DOIS EIXOS - AQUELE DA MERCANTILIZAC̣ÃO E aquele da proteção social. Entretanto, Polany ocultou as FORMAS DE INJUSTIÇA QUE NÃO ESTÃO PRESENTES NO MERCADO E TINHA UMA TENDÊNCIA A ABSOLVER AS FORMAS DE PROTEÇÃO SOCIAL QUE SÃO VETORES DE DOMINAÇÃO. ESSE CAPÍTULO AMPLIA AS ANÁLISES DO CONFLITO ENTRE MERCANTILIZAÇÃO E PROTEÇÃO SOCIAL INTEGRANDO À ANALISE UM TERCEIRO EIXO, A EMANCIPAÇĀO, ATRAVÉS DA QUAL PASSA TODO O CONFLITO. A INTRODUÇĀO DESSE TERCEIRO ELEMENTO FALTANTE TRANSFORMA O MOVIMENTO DUPLO EM UM TRIPLO, FORMANDO O CORAÇĀO DE UMA PERSPECTIVA QUASE POLANYIANA E SUSCETÍVEL DE EXPLICAR A CRISE DO SÉCULO XXI. O CAPÍTULO TEM, PRIMEIRAMENTE, A FUNÇÃO DE CONSTRUIR ESSA NOVA PERSPECTIVA E UTILIZÁ-LA EM UM SEGUNDO MOMENTO PARA A ANÁLISE DAS APOSTAS NA EMANCIPAÇÃO DA HIERARQUIA DE GÊNERO. O MOVIMENTO TRIPLO, ASSIM CONSTITUÍDO, PERMITE SUPERAR AS AMBIVALÊNCIAS DO FEMINISMO, JÁ QUE SUAS REFLEXÕES FORAM COM FREQUÊNCIA INSTRUMENTALIZADAS PELO NEOLIBERALISMO TRIUNFANTE. A REAPROPRIAÇÃO DE UMA PROTEÇÃO SOCIAL DEFINIDA POR OBJETIVOS DEMOCRÁTICOS, LOGO PARTICIPATIVOS, NÃO HIERÁRQUICOS E NÃO OPRESSIVOS, ABRE AINDA A POSSIBILIDADE DE DEFINIC̣ĀO DE UMA NOVA POLITICA FEMINISTA.

\section{PALAVRAS-CHAVE}

Capitalismo; Emancipação; Estado Providência; Feminismo; GÊNERO.

\section{ABSTRACT}

THIS ARTICLE IS A REFLECTION ON THE PERSPECTIVES OF FEMINISM IN THE CONTEXT OF THE CURRENT CRISIS OF NEOLIBERAL CAPITALISM. IT IS BASED ON THE THEORIES of Karl Polanyi that explained the historical PROCESS OF THE CRISES AS A RESULT OF THE CONFLICT BETWEEN TWO ELEMENTS - MARKETIZATION AND SOCIAL PROTECTION. HoWEVER, PolanyI KEPT OUT OF SIGHT FORMS OF INJUSTICE THAT ARE NOT PRESENT IN THE MARKET. HE ALSO HAD THE TENDENCY TO EXCUSE THE SOCIAL PROTECTION AS AN INSTRUMENT OF DOMINATION. THIS ARTICLE TAKES A BROADER VIEW ON THE ANALYSIS OF THE CONFLICT BETWEEN MARKETIZATION AND SOCIAL PROTECTION. IT INCLUDES IN THE ANALYSIS A THIRD DIMENSION, THE EMANCIPATION. THE INCLUSION OF THIS THIRD ELEMENT TRANSFORMS THE HISTORICAL PROCESS IN A THREE DIMENSIONAL CONFLICT AND FORMS THE HEART OF A QUASI-POLANYIAN PERSPECTIVE THAT IS ABLE TO EXPLAIN THE CRISIS OF THE XXI CENTURY. THIS TEXT DEVELOPS THIS NEW PERSPECTIVE AND USES IT TO ANALYZE THE BETS IN THE EMANCIPATION OF THE GENDER HIERARCHY. THE TRIPLE MOVEMENT, THUS CONSTITUTED, CAN OVERCOME THE AMBIVALENCE OF FEMINISM, AS THE FEMINIST AGENDA WAS OFTEN MANIPULATED BY NEOLIBERALISM. THE REDEFINITION OF SOCIAL PROTECTION IN DEMOCRATIC, PARTICIPATORY, NON-HIERARCHIC AND NON-OPPRESSIVE TERMS, OPENS THE POSSIBILITY TO A NEW FEMINIST POLITICS.

\section{KEYWORDS}

CAPItAlism; EMANCIPATION; Welfare State; Feminism; GENDER. 
crise atual do capitalismo neoliberal modifica a paisagem do pensamento feminista. Ao longo das duas últimas décadas, a maior parte dos teóricos homens e mulheres ${ }^{1}$ manteve-se distante da teorização social de grande alcance associada ao marxismo.

Aparentemente aceitando a necessidade de especialização universitária, esses teóricos concentraram-se neste ou naquele ramo da pesquisa de determinada disciplina, considerado como um domínio independente. Sejam eles parte do direito ou da filosofia moral, da teoria democrática ou da "crítica cultural” (cultural criticism²), seus trabalhos estão em certa medida dissociados das questões fundamentais da teoria social. Crucial para as gerações precedentes, a critica à sociedade capitalista quase desapareceu das preocupações da teoria feminista. A crítica centrada, em particular, na crise do capitalismo foi declarada redutora, determinista e ultrapassada. Atualmente, essas afirmações têm sido reduzidas a pedaços. Com o abalo do sistema financeiro mundial, o declínio da produção e do emprego no mundo e a perspectiva de uma recessão prolongada, a crise capitalista forma um incontornável pano de fundo para qualquer tentativa séria de teorização crítica.

Mas como os teóricos/as feministas devem abordar precisamente essas questões? Como ultrapassar as lacunas de um economicismo desacreditado, que se concentra exclusivamente na "lógica sistêmica" da economia capitalista? Como alcançar uma compreensão abrangente da sociedade capitalista, que não seja exclusivamente econômica, que leve em conta as ideias do feminismo, do multiculturalismo, do pós-colonialismo, do pensamento ecológico e da "virada cultural" (cultural turn ${ }^{3}$ )? Como conceituar a crise como sendo processo social ou a história e a geografia, a política, a ecologia e o direito como influentes sobre a economia? Como compreender as diferentes lutas sociais na conjuntura atual, e como avaliar o potencial de transformação social para a emancipação?

\section{Por Que Polanyi é atual?}

O pensamento de Karl Polanyi é um ponto de partida promissor para tal teorização. Em seu clássico de 1944, A Grande Transformação, ele descreve a crise capitalista como um processo histórico de múltiplas facetas que começou com a revolução industrial na Grã-Bretanha e se desenvolveu, por mais de um século, no mundo inteiro, arrastandoo à sujeição ao Império, a crises periódicas e a guerras cataclísmicas. Além do mais, para Polanyi a crise capitalista baseava-se menos no abalo da economia em sentido estrito e mais na desintegração das comunidades, no desfazimento das solidariedades e na destruição da natureza. Suas raízes mergulhavam menos nas contradições internas da economia - como a tendência à diminuição da taxa do lucro - e mais em um gigantesco reposicionamento da economia em relação à sociedade. Invertendo a relação, até então universal, segundo a qual os mercados estavam intrinsecamente 
ligados às instituições sociais e submetidos a normas morais e éticas, os partidários do "mercado enraizado" 4 buscavam construir um mundo no qual a sociedade, a moral, a ética estavam subordinadas aos mercados e modeladas por eles. Essa aspiração, intrinsecamente autodestrutiva e utópica, levou a evoluções profundamente destrutivas da sociedade humana que desencadearam em um contramovimento visando à sua proteção. É esse "movimento duplo", o da mercantilização não regulada, e em seguida o de reivindicações em favor de proteção social, que conduziu, de acordo com Polanyi, ao fascismo e à guerra mundial.

A obra de Polanyi narra, então, uma crise do capitalismo que vai além do campo acanhado do economicismo. Magistral, de grande alcance e que formula uma análise em diversos níveis, A Grande Transformação reúne em poderosa síntese histórica os protestos locais, política nacional, negócios internacionais e regimes financeiros mundiais. Como Marx, Polanyi insiste na luta social; no entanto, mais do que o conflito entre capital e trabalho, ele destaca o conflito que opõe as forças favoráveis à mercantilização e os movimentos transversais das classes em favor da proteção social. Do mesmo modo que Marx, Polanyi busca influenciar o curso da história, mas sua atitude em relação ao mercado é mais complexa. Escrito com o intuito de dar forma à ordem do pós-guerra, $A$ Grande Transformação constitui uma argumentação para a instauração de um novo regime democrático regulatório que deixariam os mercados inofensivos, sem suprimi-los totalmente.

Apenas esses elementos bastam para fazer da análise de Polanyi um ponto de partida promissor para aqueles que buscam compreender os maus dos quais sofrem a sociedade capitalista do século XXI. Mas existem outras razões, mais específicas, para nos interessarmos por ele atualmente. A história relatada em A Grande Transformação encontra forte eco nas evoluções atuais. É certo que podemos a priori explicar razoavelmente que a crise atual encontra suas raízes nos esforços recentes visando liberar os mercados da regulamentação (tanto nacional quanto internacional) instaurada após a $2^{a}$ Guerra Mundial. O que chamamos hoje de "neoliberalismo" não é nada além do que o retorno à crença no "mercado desenraizado" que prevalecia no século XIX e que desencadeou a crise capitalista descrita por Polanyi. Hoje, como àquela época, as tentativas de aplicar esse credo à vida real destroem os laços sociais, os meios de subsistência e a natureza. Hoje, como àquela época, as forças de oposição se mobilizam para colocar fim a essas destruições. À primeira vista, a crise atual pode ser considerada como o "retorno de A Grande Transformação".

O ponto de vista de Polanyi é, por múltiplas razões, promissor para a teorização atual. No entanto, os/as feministas não o devem adotar cegamente. Olhando mais de perto, mesmo ultrapassando o economicismo, a obra de Polanyi se mostra muito imperfeita. Decididamente ligado aos maus provenientes dos mercados "desenraizados" (désencastrés ${ }^{5}$ ), ele ignora aqueles cuja origem está em outro lugar, na "sociedade" envolvente. Ocultando as formas de injustiça que não repousam sobre o 
mercado, ele tem, igualmente, a tendência de absolver as formas de proteção social que são vetores de dominação. Ligado, excessivamente, às lutas contra as degradações causadas pelo mercado, ele negligencia as lutas contra as injustiças ancoradas na "sociedade" e codificadas nas proteções sociais.

É por isso que os teóricos feministas não devem adotar o quadro de Polanyi tal como aparece em $A$ Grande Transformação. É necessário remodelar esse quadro para alcançar uma nova concepção quase polanyiana da crise do capitalismo, que evita não somente o economicismo redutor, mas também uma leitura romanceada da "sociedade".

Esse é o meu objetivo aqui. Buscando desenvolver uma crítica que engloba a "sociedade" e a "economia", eu proponho dar alcance maior à problemática de Polanyi a fim de incluir um terceiro projeto histórico de luta social que redesenha o conflito, central para Polanyi, entre mercantilização e proteção social. Esse terceiro projeto histórico, que chamarei de "emancipação", visa afrouxar as formas de sujeição ancoradas na "sociedade". Centrais às duas manifestações de $A$ Grande Transformação, tanto aquela analisada por Polanyi quanto a que vivemos atualmente, as lutas por emancipação constituem um terceiro eixo faltante pelo qual passa todo o conflito entre mercantilização e proteção social. A introdução desse terceiro faltante terá por efeito transformar o movimento duplo em triplo, englobando a mercantilização, a proteção social e a emancipação.

O movimento triplo formará o coração de uma nova perspectiva quase polanyiana suscetível de explicar a crise capitalista do século XXI. Em um primeiro momento, aplicar-me-ei à construção dessa nova perspectiva que, em um segundo momento, servirá para a análise de certas ambivalências da política feminista.

\section{Os conceitos chave de Polanyi: mercados "Desenraizados", PROTEÇÃO SOCIAL E MOVIMENTO DUPLO}

Começarei lembrando a distinção feita por Polanyi entre mercados "enraizado" (encastré) e "desenraizado" (désencastrés). Parte integrante de A Grande Transformação, essa distinção comporta conotações fortes, que devem ser objeto de um exame crítico.

Polanyi distingue duas diferentes relações que os mercados podem manter com a sociedade. De um lado, os mercados podem ser "enraizados", imbricados em instituições não econômicas e regidos por normas não econômicas, tais como "preço justo" e "salário justo". De outro lado, os mercados podem ser "desenraizados", livres de controle extraeconômicos e regidos de modo imanente pela oferta e pela demanda. Segundo Polanyi, a primeira possibilidade constitui a norma histórica. Através da história, nas diferentes civilizações e em lugares muito distantes, os mercados foram submetidos a controles não econômicos, que colocaram limites ao que pode ser vendido e comprado, aos atores desse comércio e às suas modalidades. A segunda possibilidade constitui uma anomalia histórica. Invenção britânica do século XIX, o 
mercado "desenraizado" é, de acordo com Polanyi, uma ideia totalmente nova cujo desdobramento ameaça o tecido da sociedade humana.

Para Polanyi, os mercados, em realidade, não podem jamais ser totalmente desenraizados da sociedade em seu conjunto. Toda tentativa nesse sentido estará inexoravelmente consagrada ao fracasso. De um lado, os mercados só podem funcionar corretamente em um contexto não econômico de sistema de valores e de relações solidárias. As tentativas que visam desenraizá-lo destroem esse contexto. De outro lado, a tentativa de estabelecer mercados autorregulados se mostra tão destrutiva para o tecido social que suscita importantes reivindicações em favor de sua regulação social. Longe de reforçar a cooperação social, o projeto de "desenraizamento" dos mercados provoca, inevitavelmente, uma crise social.

São nesses termos que $A$ Grande Transformação descreve uma crise do capitalismo que foi da revolução industrial à $2^{a}$ Guerra Mundial. Além disso, para Polanyi, a crise englobava não apenas os esforços dos interesses comerciais para "desenraizar" os mercados, mas também a combinação de contra-esforços utilizados pelos proprietários de terra, pelos trabalhadores urbanos e por outras camadas sociais para defender a sociedade contra a "economia". Enfim, para Polanyi, é a acentuação da luta entre esses dois campos, os partidários da mercantilização e aqueles da proteção social, que deram à crise a forma característica de um "movimento duplo". Se a primeira dimensão desse movimento nos conduziu de uma fase mercantilista, na qual os mercados eram socialmente e politicamente regulados, a uma fase de laisser-faire, na qual eles (os mercados) se tornaram relativamente desregulados, a segunda dimensão deveria nos levar, ao menos era o que esperava Polanyi, a uma nova fase, na qual os mercados seriam regulados novamente pelo Estado Providência democrático. O efeito seria recolocar a economia no lugar que ela deve ocupar na sociedade.

De modo geral, a distinção entre mercado “enraizado" e “desenraizado" se aplica a todos os conceitos centrais de Polanyi, neles compreendidos a sociedade, a proteção social, a crise e o movimento duplo. Ponto igualmente importante, a distinção está implícita, mas, sem nenhuma dúvida, é normativa. Os mercados "enraizados" estão associados à proteção social, considerada como um refúgio em face da fúria dos elementos. Os mercados "desenraizados" são associados à explosão, a ter que se nadar nu nas "águas geladas do cálculo egoísta” (Marx e Engels, 1848). Essas apreciações (mercados “enraizados" são bons e mercados "desenraizados” são ruins) também participam do movimento duplo. O primeiro movimento (exposição) traz perigos, o segundo (proteção) traz segurança.

O que devemos concluir? À primeira vista, a distinção entre mercados "enraizados" e "desenraizados" tem muito a oferecer para a teoria feminista. Por um lado ela ultrapassa o economicismo para chegar a uma conclusão mais abrangente da crise capitalista como processo histórico de múltiplas facetas, tanto sociais, políticas e ecológicas, como econômicas. Por outro lado, ela ultrapassa o funcionalismo interpretando a crise 
não como uma "ruptura objetiva do sistema", mas como um processo intersubjetivo que inclui a reação dos atores sociais às modificações que lhe são perceptíveis em suas próprias vidas e em suas relações uns com os outros. Ainda nesse caso, a distinção de Polanyi permite uma crítica da crise que não rejeita os mercados enquanto tais, mas apenas os que são nefastos e "desenraizados". Por consequência, o conceito de um mercado "enraizado" oferece a perspectiva de uma alternativa progressista devido ao “desenraizamento" absurdo preconizado pelos neoliberais e à supressão sistemática dos mercados que tem tradicionalmente o favor dos socialistas.

Não obstante, o que está implícito nas categorias definidas por Polanyi é problemático. De um lado, sua descrição dos mercados "enraizados" e das proteções sociais são acentuadamente idílicas. Ao romancear a "sociedade", ele oculta o fato de que as sociedades nas quais os mercados sempre foram "enraizados” são também lugares de opressão. Ao contrário, a descrição que Polanyi dá do "desenraizamento" é um tanto sombria. Tendo idealizado a sociedade, ela oculta o seguinte fato: sejam quais forem as demais consequências dos processos que desenraizam os mercados das proteções opressivas, eles trazem consigo um aspecto emancipatório.

Também, os teóricos feministas de hoje devem remodelar esse quadro. Evitando tanto a condenação em massa do "desenraizamento" como a aprovação em massa do "reinraizamento", nós devemos submeter a um exame crítico as duas dimensões do movimento duplo. Tornando visíveis os déficits normativos da "sociedade" assim como os da "economia", nós devemos provar a justiça das lutas contra a opressão de onde quer que ela venha.

Para tanto, eu proponho a utilização de um recurso do qual Polanyi não fez uso: as ideias dos movimentos feministas. Trazendo à tona as assimetrias do poder que ele ocultou, esses movimentos expuseram a face oculta e predatória dos mercados "enraizados" que ele tinha tendência a idealizar. Insurgindo-se contra as proteções que também constituem opressões, elas (as ideias dos movimentos feministas) fizeram nascer reivindicações em favor da emancipação. Com base no ideário feminista, eu proponho repensar retrospectivamente o movimento duplo em relação aos combates feministas pela emancipação.

\section{A EMANCIPAÇÃO: O "TERCEIRO" FALTANTE}

Ao falar em emancipação, nós introduzimos uma categoria que não aparece em $A$ Grande Transformação. Mas a ideia - e mesmo o termo - de emancipação era usual na época em que fala Polanyi. Para demonstrar isso, basta pensar nas lutas de então, que visavam abolir a escravidão, emancipar as mulheres e libertar os povos não europeus sob o jugo colonial. Esses combates sempre levaram o nome de "emancipação". É de fato estranho que essas lutas não figurem numa obra que pretendia descrever a grandeza e a decadência daquilo que ele chama de "civilização do século XIX”. Meu objetivo 
não é simplesmente assinalar essa omissão, mas sublinhar que as lutas por emancipação colocaram em destaque diretamente as formas opressivas da proteção social, sem condenar totalmente nem celebrar absolutamente a mercantilização. Se esses movimentos tivessem sido incluídos em $A$ Grande Transformação, elas teriam desestabilizado a trama narrativa dualista e, assim, faria explodir o movimento duplo.

Para compreender o porquê, consideremos que a emancipação difere fortemente da principal categoria positiva de Polanyi: a proteção social. Assim, a proteção social se opõe à exposição e a emancipação se opõe à dominação. Enquanto a proteção visa proteger a "sociedade" dos efeitos desintegradores dos mercados não regulados (marchés non régulés), a emancipação visa jogar luz na dominação de onde quer que ela venha; tanto da sociedade quanto da economia. Se a ideia principal de proteção é sujeitar as trocas mercantis a normas não econômicas, a da emancipação é a de submeter as trocas mercantis e as normas não mercantilistas a um exame crítico. Enfim, os valores supremos da proteção são a segurança, a estabilidade, e a solidariedade social, enquanto que a prioridade da emancipação é combater a dominação.

Contudo, estaríamos errados ao concluir que a emancipação "anda sempre de mãos dadas" com a mercantilização. Se a emancipação se opõe à dominação, a mercantilização se opõe à regulação extraeconômica da produção e das trocas, pouco importando seu objetivo, proteger ou emancipar. Enquanto a mercantilização defende a suposta autonomia da economia e se previne da influência de outras esferas, a emancipação ultrapassa as fronteiras que delimitam as esferas, buscando extrair a dominação de cada esfera. A ideia principal da mercantilização é liberar a compra e a venda de normas morais e éticas, enquanto a emancipação busca examinar em profundidade todos os tipos de normas do ponto de vista da justiça. Enfim, enquanto a mercantilização faz da eficiência, da escolha individual e da liberdade negativa ${ }^{6}$ seus mais altos valores, a prioridade da emancipação, como acabo de dizer, é o de combater a dominação.

Desse modo, as lutas pela emancipação não se sobrepõem perfeitamente a nenhuma das duas dimensões do movimento duplo de Polanyi. Por um lado, essas lutas parecem convergir para a mercantilização em alguns momentos como, por exemplo, quando qualificam como opressivas as proteções sociais que os partidários do liberalismo econômico buscam erradicar. Por outro lado, elas convergem com os projetos que defendem as proteções sociais como, por exemplo, quando denunciam os efeitos opressores da desregulação. De outro modo, ainda, as lutas pela emancipação divergem das duas dimensões do movimento duplo como, por exemplo, quando elas não buscam suprimir e defender as proteções existentes, mas, sobretudo, procuram transformar o modo de proteção. Assim, as convergências, quando existem, são conjunturais e contingentes. Não estando totalmente alinhadas à proteção e à desregulação, as lutas pela emancipação representam uma terceira força que rompe 
o esquema dualista de Polanyi. Para fazer justiça a essas lutas, é necessário revisar o quadro de Polanyi e transformar seu movimento duplo em triplo.

\section{EMANCIPAÇÃO E PROTEÇÕES HIERÁRQUICAS}

Para compreender porque interessamo-nos pelas reivindicações feministas à emancipação, basta notar que tais reivindicações despedaçam o movimento duplo revelando como as proteções sociais podem ser opressoras ao institucionalizar uma hierarquia de status. Essas proteções privam certos indivíduos, que deveriam em princípio ser incluídos como membros da sociedade, de condições prévias a uma participação plena na vida social. O exemplo clássico é a hierarquia entre sexos que dá às mulheres um status inferior, comparável frequentemente àquele de uma criança do sexo masculino, e que com frequência impede as mulheres de participar plenamente, em pé de igualdade com os homens, das interações sociais. Mas poderíamos também citar as hierarquias de casta, nelas compreendidas as que se fundam em ideologias racistas. Em todos esses casos, as proteções sociais são favoráveis aos indivíduos que se encontram no topo da hierarquia de status e concedem vantagens menores (ou nenhuma) àqueles que se encontram mais baixo na hierarquia. Por consequência, elas protegem menos a própria sociedade que a hierarquia social. Então, não é surpreendente que os movimentos feministas, antirracistas e anticastas tenham se mobilizado contra as hierarquias, rejeitando as proteções que elas pretendem oferecer. Insistindo na participação plena e inteira na sociedade, eles buscam desmantelar os dispositivos que as privam dos pré-requisitos sociais para ascender a uma "paridade de participação” (parity of participation, ver abaixo: A “paridade de participação”).

\section{A paridade de participação (parity of participation)}

Dou à expressão "paridade de participação" (ou "paridade participativa”) um sentido mais amplo que aquele de "paridade" à francesa, e isso por meio de cinco pontos de vista ${ }^{7}$.

Primeiramente, a paridade não é para mim uma questão de números. Ela não deve ser reduzida a uma lei exigente na qual as mulheres sejam metade do eleitorado. Trata-se, sobretudo, de um estado qualitativo: ser igual, estar em igualdade com os outros, interagir com os outros em pé de igualdade; algo que os números não podem garantir.

Em segundo lugar, a paridade não pode concernir à única dimensão da representação. O obstáculo a uma participação igualitária das mulheres na vida política não é somente a estrutura do poder político. Ao contrário, eu penso que a "participação paritária" (parity of participation), deve levar em conta três dimensões da dominação: a distribuição econômica, o reconhecimento cultural e legal e a representação 
política. Essas desigualdades de distribuição e de reconhecimento, tanto quanto aquelas de representação, podem constituir (e constituem com frequência) um obstáculo à paridade.

Em terceiro lugar, penso que a paridade deve se aplicar a todos os aspectos da vida social e não somente às instituições políticas. Assim, a justiça exige dela uma "paridade de participação" em uma multiplicidade de domínios de interação, notadamente os mercados de trabalho, as relações sexuais, a vida das famílias, as esferas públicas e as associações da sociedade civil.

Em quarto lugar, a paridade não deve concernir somente ao eixo de diferenciação que é o sexo, mas também outras categorias subordinadas (tais como as minorias raciais, éticas e religiosas). Especialmente que uma lei somente sobre a paridade entre os sexos pode ter um impacto negativo sobre a representação dessas categorias: as medidas visando corrigir um tipo de disparidade podem de fato exacerbar outras. A justiça exige uma "paridade participativa" que diga respeito aos principais eixos de diferenciação social, sem exclusividade.

A quinta diferença concerne à maneira de coloca-a em prática. A lei francesa, por exemplo, requer uma paridade real. Ao contrário, penso que a moral quer que a sociedade garanta aos seus membros uma possibilidade de paridade, caso eles desejem participar de uma atividade ou interação no momento de sua escolha. Não é necessário que cada um participe efetivamente das atividades em questão.

Minha concepção de justiça em matéria de "paridade participativa" é, então, muito mais ampla do que a concepção de paridade na política, porque ela estabelece uma norma que permite avaliar a justiça em todos os arranjos sociais, ao levar em conta as três dimensões e os múltiplos eixos de diferenciação social.

A crítica feminista da proteção hierárquica é apresentada em todas as épocas da história contadas por Polanyi, mesmo que ele não faça menção a ela. Durante o período mercantilista, os/as feministas como Mary Wollstonecraft criticaram os dispositivos sociais tradicionais que enraizavam os mercados. Condenando as hierarquias de gênero enraizadas na família, na religião, no direito e nos usos sociais, eles/elas exigiam que fossem dadas às mulheres as condições indispensáveis à "paridade de participação", tão fundamentais quanto uma personalidade jurídica independente, a liberdade de religião, a educação, o direito de recusar relações sexuais, os direitos de guarda das crianças, assim como a lei de se exprimir em público e de votar. Durante o período do laisser-faire, os/as feministas exigiam uma igualdade de acesso ao mercado. Denunciando a instrumentalização das normas sexistas por este último, eles/elas se opunham às proteções que proibiam as mulheres de possuírem bens, de assinar contratos, de dispor de seu salário, de exercer certas profissões, de trabalhar durante os mesmos horários e de receber o mesmo salário dos homens, como pré-requisitos a uma participação plena e por inteiro da vida social. Durante o período que se seguiu à $2^{\text {a }}$ Guerra Mundial, os/as 
feministas da segunda geração atacaram o "patriarcado público" instituído pelo Estado Providência. Condenando as proteções sociais fundadas no "salário familiar" 8 , eles/ elas reivindicaram para as mulheres uma remuneração igual para um trabalho de valor comparável, prestações sociais tratando a igualdade, o cuidado (care), o trabalho remunerado, e a supressão da divisão sexual do trabalho, seja ele remunerado ou não.

Em cada uma das épocas os feministas reivindicaram a emancipação, com o objetivo de ultrapassar a dominação. Às vezes, eles/elas tinham por alvo as estruturas sociais tradicionais que enraizavam o mercado; outras vezes, eles/elas visavam às forças que desenraizavam os mercados; e outras vezes ainda, eles/elas atacavam as forças que reinraizavam os mercados. Desse modo, as reivindicações feministas jamais foram fundadas de modo sistemático sobre qualquer das duas dimensões do movimento duplo de Polanyi. Pelo contrário, suas lutas pela emancipação constituíam uma terceira dimensão do movimento social, que atravessava os outros dois. O que Polanyi chamava de movimento duplo era em realidade um movimento triplo.

\section{CONCEITUAÇÃO DO MOVIMENTO TRIPLO}

Como devemos, então, compreender o movimento triplo? Esse conceito apresenta a crise do capitalismo como um conflito de três dimensões: mercantilização, proteção social e emancipação. Cada um é compreendido como irredutível no plano conceitual, normativamente ambivalente e inextricavelmente imbricado com os outros dois. Nós já vimos, contra Polanyi, que a proteção social é com frequência ambivalente: ela permite não submeter os efeitos desintegradores da regulação, ao institucionalizar uma dominação. Mas como veremos adiante, isso vale também para os outros termos. A desregulação dos mercados produz, evidentemente, os efeitos negativos que Polanyi sublinhou, mas pode igualmente gerar efeitos positivos quando as proteções que ela desintegra são fontes de opressão, por exemplo, pela introdução do mercado em países comunistas burocratizados, ou ao permitir que antigos escravos tenham acesso ao mercado de trabalho. A emancipação também não é isenta de ambivalências, na medida em que ela gera não somente uma liberação, mais também rupturas na rede de solidariedades existentes. Assim, ao destruir a dominação, a emancipação pode também destruir as bases da ética solidária da proteção social e encorajar assim a mercantilização.

Visto desse ângulo, cada termo se caracteriza, por vezes, por um telos que lhe é próprio e por uma ambivalência potencial que aparece em sua interação com os outros dois termos. Nenhum dos três pode ser apreendido corretamente se for considerado independentemente dos outros. Bem como a área social não pode ser apreendida corretamente se apenas nos interessarmos por dois desses termos. Uma visão adequada da crise capitalista só se caracteriza a partir do momento em que os três são examinados conjuntamente. 
É, então, aqui que se encontra a primeira condição desse movimento triplo: a relação entre duas dimensões quaisquer desse conflito tridimensional passa obrigatoriamente pela mediação do terceiro. Assim, como acabei de indicar, o conflito entre mercantilização e proteção social deve passar pela mediação da emancipação. $O$ mesmo ocorrerá quando eu mostrar, logo em seguida, que os conflitos entre proteção e emancipação devem passar pela mediação da mercantilização. Nesses dois casos, a mediação pela terceira dimensão é indispensável à díade. Negligenciar esse terceiro seria revisitar o falseamento da lógica da crise capitalista e do movimento social.

\section{MudAR de PERSPECTIVA: A AMBIVALÊNCIA DA EMANCIPAÇÃO NA NOVA E GRANDE TRANSFORMAÇÃO}

Até aqui, eu me apoiei nesse movimento triplo para explorar a ambivalência da proteção social. Agora, eu desejo mudar de perspectiva e me apoiar sobre o movimento triplo para explorar a ambivalência da emancipação. Tendo sublinhado a necessidade de compreender os conflitos entre desregulação e proteção social passando pela mediação da emancipação, mediação negligenciada por Polanyi, acredito ser necessário, nesse momento, sublinhar a necessidade de compreender os conflitos entre proteção e emancipação passando pela mediação da mercantilização, o que acredito ter sido negligenciado por correntes importantes do movimento feminista.

Em razão disso, em relação a esse ponto, coloco-me na perspectiva da "grande transformação" da nossa época. No caso desta transformação, comecemos com o "liberalismo enraizado" (Ruggie, 1992) instaurado após a 2a Guerra Mundial. Baseado em um quadro regulamentar internacional conhecido pelo nome de Bretton Woods, o liberalismo "enraizado" englobava os Estados Providência keynesianos dos países ricos e os Estados "desenvolvimentistas" 9 pós-coloniais. Não obstante, desde os anos 1980, esses dispositivos foram submetidos à pressão do neoliberalismo, que defendia um novo desenraizamento dos mercados, provocando a mesma crise capitalista, a mais profunda desde a Grande Depressão.

Mais globalmente, meu objetivo é de analisar a crise atual por meio do conceito do movimento triplo, assim como Polanyi se apoiou sobre o movimento duplo para compreender a crise precedente. Para mim, como para ele, o objetivo é de clarificar as perspectivas de uma nova onda de "reinraizamento" democrático, estabilizado por um sistema mundial de regulação econômica. No entanto, em relação ao que me interessa, a proteção social deve ser reexaminada à luz da emancipação. Devemos, então, imaginar os dispositivos de "reinraizamento" dos mercados usados para superar a dominação.

Que luz o movimento triplo pode jogar nessa questão? Em nossa época, cada uma dessas três orientações possui seus partidários. A mercantilização é defendida com fervor pelos neoliberais. A proteção social suscita defesas diferentes e variadas 
- algumas agradáveis, outras menos - vinda de socialdemocratas e de sindicalistas nacionalistas, de movimentos populistas que se opõem à imigração, de movimentos religiosos neo-tradicionais, ou ainda de militantes antiglobalização, ecologistas e populações autóctones. A emancipação é o cavalo de batalha dos novos movimentos sociais, notadamente os multiculturalistas, os/as feministas do mundo inteiro, os partidários da liberação lésbica/gay, os apóstolos da democracia cosmopolita, os militantes dos direitos do homem ou ainda os defensores de uma justiça mundial. São essas as relações complexas entre esses três tipos de projetos que imprimem a forma de um movimento triplo à crise atual da sociedade capitalista.

Estudemos, agora, o papel dos projetos de emancipação no seio dessa constelação. Desde pelo menos os anos 1960, tais movimentos levantaram-se contra os aspectos opressores da proteção social do liberalismo “enraizado". Àquela época, por exemplo, os New Leftists expuseram à luz do dia o caráter opressor dos regimes de proteção social de organização burocrática, que escravizam seus beneficiários. Do mesmo modo, os anti-imperialistas revelaram o caráter opressor das proteções sociais dos países ricos, que eram financiados por uma troca desigual, à custa das antigas populações coloniais. Mais recentemente, os multiculturalistas mostraram o caráter opressor das proteções sociais construídas sob o autocentrismo dos membros da maioria religiosa ou etnocultural, que penaliza os membros dos grupos minoritários. Enfim, o aspecto mais importante na minha perspectiva: os/as feministas da segunda geração fizeram aparecer o caráter opressor das proteções sociais construídas sob as hierarquias de gênero.

Em cada caso, o movimento colocou em epígrafe um tipo de opressão e formulou uma reivindicação de emancipação correspondente. No entanto, em cada caso, igualmente, as reivindicações do movimento eram ambivalentes: elas podiam, em princípio, seguir no sentido tanto da mercantilização quanto da proteção social. No primeiro caso, quando a emancipação segue no sentido da mercantilização, ela servia para minar não apenas a dimensão opressora, mas também a própria proteção social. No segundo caso, quando a emancipação segue no sentido da proteção social, ela servia não a minar, mas, sobretudo, a transformar o modo de proteção.

Esse argumento vale, em minha opinião, para todos os movimentos de emancipação que acabo de citar. Não obstante, concentrar-me-ei aqui na crítica que o feminismo da segunda geração formula contra a dimensão opressora da proteção social no liberalismo "enraizado". Conforme penso, esse movimento é muito frequentemente visto como engajado em uma luta binária. Focado em sua oposição às proteções opressoras, ele não era sempre suficientemente consciente da terceira dimensão desse movimento triplo, a saber, os esforços visando desregular os mercados. Negligenciando a ascensão do neoliberalismo, os/as feministas da segunda geração compreenderam mal a situação e avaliaram mal as prováveis consequências de suas ações. Sua incapacidade de perceber o papel de mediação que a mercantilização 
faz no conflito entre emancipação e proteção social dá forma ainda hoje ao curso da crise capitalista do século XXI.

\section{AmbivalênCias feministas}

Lembremo-nos que o feminismo da segunda geração atacou a hierarquia de gênero das proteções sociais no Estado providência do pós-guerra. Nos Estados Unidos, isso significou colocar em destaque o caráter sexual implícito de um sistema cindido entre, de uma parte, a assistência aos pobres, às crianças, às mulheres e aos estigmatizados; de outra parte, uma assistência social respeitável para aqueles considerados como "trabalhadores". Na Europa, isso significou revelar uma hierarquia androcêntrica na divisão entre prestação e direitos derivados destinados às mães e os direitos sociais associados a um trabalhador assalariado. Nos dois casos, os/as feministas perceberam que havia traços de um esquema mais antigo, herdado do período anterior à guerra, chamado de "salário familiar". Nesse esquema, o arquétipo do cidadão era um homem provedor de recursos e pai de família, no qual o salário era o principal, de fato único, sustento econômico de sua família e, se sua esposa ganhasse um salário, esse serviria apenas de apoio. Esse ideal profundamente sexual de um salário "familiar" constituía o plano central da substância ética sobre a qual se apoiavam os Estados providência para "reinraizar" os mercados. Normalizando a dependência das mulheres, o sistema de proteção social comprometia as chances das mulheres de participar plenamente, em igualdade com os homens, na vida da sociedade. Institucionalizando as concepções androcêntricas da família e do trabalho, tornava-se natural a hierarquia de sexos e afastava toda contestação política. Ponto igualmente importante, ao valorizar o trabalho assalariado, o modo de proteção proposta pelo liberalismo "enraizado" obscurecia a importância social do care (Fraser, 1989, 1997 e 2005).

Tal era a crítica feminista do liberalismo "enraizado". Politica e intelectualmente poderosa, tal crítica não era menos ambivalente, ou seja, suscetível de seguir tanto em uma direção quanto na outra. Num primeiro sentido, a crítica do "salário familiar” formulada pelos/pelas feministas visava conceder às mulheres um acesso pleno e integral ao emprego e aos direitos relacionados a tal condição, em igualdade com os homens. Essa opção tendia a valorizar o trabalho assalariado e o ideal androcêntrico da independência individual, o que leva novamente, de facto, a desvalorizar o care, a interdependência e a solidariedade. Ao atacar o ethos tradicional do gênero, que servia ainda a enraizar os mercados, essa forma de feminismo é suscetível in fine de reforçar o desenraizamento. Ele poderia ter como efeito, intencional ou não, que a luta contra a hierarquia entre os sexos seguisse no sentido da mercantilização.

Contudo, a crítica feminista contra a proteção opressora poderia, em princípio, tomar outro caminho. Articulada de modo diferente, essa luta por emancipação 
poderia se apoiar sob a segunda dimensão do movimento triplo, a saber, a proteção social. Nesse segundo cenário, a crítica feminista visaria rejeitar os valores androcêntricos, e em particular a supervalorização do trabalho assalariado e à subvalorização do care, trabalho não assalariado. Ao levar este último ao posto de questão de importância pública, esse movimento se aplicaria a repensar os dispositivos sociais de modo a permitir a cada um, homem ou mulher, conciliar esses dois tipos de atividade, ao superar as tensões que pesam sobre essas tentativas hoje em dia. Rejeitando igualmente a oposição dependência/independência sobreposta à oposição mulher/homem, um feminismo favorável à proteção social contribuiria para romper o vínculo falacioso entre hierarquia social e dependência, que constitui uma característica universal da condição humana. Valorizado a solidariedade e a interdependência, a crítica contribuiria não a dissolver, mas a transformar as proteções sociais.

De fato, o feminismo da segunda geração englobava essas duas orientações. No tocante ao essencial, os/as feministas liberais ou radicais se inscreviam na lógica da mercantilização, enquanto os/as feministas socialistas e os/as feministas de cor tinham uma tendência maior a sustentar a proteção social. No primeiro caso, esse alinhamento nem sempre era intencional: todos os/as feministas liberais e radicais não buscavam intencionalmente substituir o modelo do "salário familiar" por aquele da família com duas fontes de renda. Mas, não conseguindo recolocar sua luta por emancipação dentro do contexto do movimento triplo, eles/elas podiam in fine acentuar o desenraizamento e a desregulação. No outro caso, em contrapartida, o alinhamento era relativamente consciente. Os/as feministas para os quais as preocupações concordavam com as correntes favoráveis à proteção apreenderam intuitivamente a lógica do movimento triplo. Eles/elas tinham com frequência o sentimento que sua luta por emancipação coincidia, ao confirmar, outra luta, aquela entre proteção e desregulação. Ao se posicionar em um jogo tridimensional eles/ elas queriam evitar o encorajamento dos proponentes da desregulação, ainda que se colocar vigorosamente contra as proteções fontes de opressão.

Poderíamos dizer que tal ambivalência do feminismo foi resolvida, nesses últimos anos, em favor da mercantilização. Insuficientemente atentos/as à ascensão do fundamentalismo de mercado, os/as feministas da corrente dominante terminaram por fornecer razões que justificam um novo modo de acumulação do capital, largamente dependente do trabalho remunerado das mulheres. Porque as mulheres de todas as classes, origens éticas e nacionalidades afluíram para os mercados de trabalho de todo o planeta, a ideologia do "salário familiar" está dando lugar à norma mais recente e mais moderna do lar com duas pessoas remuneradas. Pouco importa que esse novo ideal se concretize por uma redução dos níveis salariais, uma precarização do emprego, um recuo do nível de vida, um aumento significativo no tempo gasto com o trabalho remunerado em relação ao gasto no lar, na multiplicação de postos duplos (e mesmo, com frequência, de postos triplos ou quádruplos) 
e de um aumento do número de lares dirigidos por uma mulher. A ideologia neoliberal conseguiu transformar uma mula em cavalo de corrida ao se apropriar da crítica feministas do "salário familiar".

Essa crítica fornece daqui em diante uma boa parte do "novo espírito do capitalismo” (Boltanski e Chiapello, 2005), quer dizer, a matéria simbólica e ética que permite embelezar o novo "capitalismo flexível”, conferindo a ele uma significação superior e um peso moral. Ao conferir às lutas cotidianas uma significação ética, o discurso feminista atrai as mulheres das duas extremidades da escala social: em uma extremidade, as mulheres das classes médias, determinadas a quebrar o teto de vidro; em outra, as mulheres interinas, trabalhadoras em tempo parcial, assalariadas de baixa renda, empregadas domésticas, trabalhadoras do sexo, imigrantes, trabalhadoras em zonas francas industriais e clientes em estabelecimentos de microcrédito, em busca não somente de renda e segurança material, mas também de dignidade, de bem-estar e de uma liberação da autoridade tradicional. Nas duas extremidades, o sonho de emancipação das mulheres é sacrificado no altar do capitalismo. Em consequência, a crítica do "salário familiar" formulada pelos/as feministas se tornou compatível com a mercantilização. Outrora, capaz de andar no sentido da proteção social, ela serve mais e mais a intensificar a valorização do trabalho assalariado levada adiante pelo neoliberalismo (Fraser, 2009).

\section{Por uma NOVA AliAnÇA ENTRE EMANCIPAÇÃo E PROTEÇÃo SOCIAL}

O que podemos concluir? Certamente não que o feminismo da segunda geração simplesmente fracassou. Tampouco que ele deva ser responsabilizado pelo triunfo do neoliberalismo, nem, evidentemente, que as lutas por emancipação são intrinsecamente problemáticas. Nem mesmo que os ideais de emancipação são sempre, e desde o início, destinados a serem restabelecidos para os fins da mercantilização. Eu concluo, sobretudo, que nós, aqueles que desejam que as mulheres se emancipem da hierarquia de gênero, devemos tomar mais consciência dos desenvolvimentos passados, pois agimos sobre um terreno igualmente ocupado por forças de mercantilização.

Voltemos às questões mais gerais que inspiraram esse capítulo. Refletindo sobre a grande transformação que conhecemos atualmente, eu, efetivamente, reconstruí o projeto de Polanyi. Ao teorizar o movimento duplo, ele descrevia os conflitos de sua época sob os traços de uma luta histórica pela alma do mercado. Serão a natureza, o trabalho e o dinheiro despidos de toda significação ética, divididos e negociados como mercadorias quaisquer, sem respeito algum pelas consequências? Ou serão os mercados submetidos a uma regulação política que leve em conta a ética e a moral? No século XXI, essa luta nunca antes foi tão intensa. De qualquer modo, o movimento triplo a ilumina de modo mais cru, conforme ele é transpassado por duas outras 
lutas de importância histórica. Uma é a luta pela alma da proteção social. Os dispositivos que reinraizam os mercados na era pós-neoliberal serão opressores ou emancipatórios, hierárquicos ou igualitários, e, poderia ainda dizer, bem ou mal enquadrados, hostis ou favoráveis à diferença, burocráticos ou participativos? Esta luta jamais foi tão intensa. Mas ela é transpassada por outra luta histórica: aquela pela alma da emancipação. As lutas de emancipação do século XXI servirão ao progresso do desenraizamento e da desregulação dos mercados? Ou servirão elas para expandir e democratizar as proteções sociais e torna-las mais justas?

Essas questões sugerem um projeto possível para aqueles e aquelas favoráveis à emancipação. Podemos tentar romper nossas ligações perigosas (Einsenstein, 2005) com a mercantilização e criar uma nova aliança com os partidários da proteção social. Assim, ao reconfigurar um movimento triplo, nós podemos integrar a preocupação central do combate contra a dominação àquelas igualmente fundamentais, da solidariedade e da segurança sociais, sem, contudo negligenciar a importância da liberdade negativa. Ao adotar uma concepção mais abrangente de justiça social, tal projeto poderá, ao mesmo tempo, homenagear o pensamento de Polanyi e remediar suas insuficiências.

NOTAS

* Eu agradeço pelos comentários preciosos e pelas discussões frutíferas que me permitiram, Amy Allen, Seyla Benhabib, Robin Blackburn, Luc Boltanski, Hauke Brunkhorst, Robin Celikates, Alessando Ferrara, Rainer Forst, Rahel Jaeggi, Françoise Milewski, David Owen, Réjane Sénac-Slawinski e Eli Zaretsky.

1 NT. A autora utiliza os termos "théoriciens-nes" todas as vezes que se refere a "teóricos". Na inexistência do feminimo na língua portuguesa, utilizamos na primeira vez "teóricos homens e mulheres”, mas em todas as outras apenas "teórico/s". Seguimos no original sempre que possível a utilização dos substantivos no feminino e no masculino, assim como "eles-elas”, "aqueles-aquelas”, etc.

2 Nota da redação francesa: a expressão "crítica cultural” cultural criticism faz referência a um conceito abrangente da "cultura", na medida em que engloba uma dimensão mais geral, em particular social, histórica, filosófica, antropológica, etc. Se o conceito surgiu no século XIX, ele foi ampliado no século XX, no quadro de uma crítica radical do sistema de valores da sociedade. A “crítica cultural” restaura a capacidade crítica a um campo que tinha uma tendência a se institucionalizar. Para além de uma cultura entendida como um conjunto concreto de crenças e de práticas partilhadas por um grupo humano, a "crítica cultural", interroga-se também sobre a ausência de uma cultura coerente, estável e acabada, e destaca as contradições entre os diferentes elementos de uma cultura, a falta de integração, a importância das resistências, a aptidão das culturas à mistura 
e à modificação, à construção de identidades individuais e sociais. Dimensão semiótica de toda atividade humana, a cultura é vista como um sistema coerente e estruturado de símbolos, e um conjunto de práticas e recursos mobilizáveis para a ação.

A "virada cultural” (cultural turn) faz referência a esses movimentos críticos da segunda metade do século XX, que ultrapassaram as fronteiras disciplinares e religaram a crítica cultural às outras esferas das ciências sociais que esses movimentos também influenciaram fortemente.

3 Ver nota anterior.

4 As palavras utilizadas no original são "encastré/désencatré/réencastré", que a semelhança do termo "embbeded”, no inglês, encontram a melhor tradução por "enraizado/desenraizado/reinraizado".

5 Ver nota 4.

6 Nota da redação francesa: a liberdade negativa aqui se refere ao conceito estabelecido por Isaiah Berlin (Dois conceitos de liberdade, 1969). A liberdade negativa é a ausência de entraves exercidos pelos outros. Quanto maior for o espaço de não interferência, maior é minha liberdade. Berlin se opõe às filosofias iluministas, das quais ele critica a concepção autoritária de liberdade. Seus trabalho são retomados por Friedrich von Hayek (The Constitution of Liberty, 1960; Law, Legislation and Liberty, 1973): a liberdade negativa, enquanto ausência de interferência coercitiva, tornar-se-á uma base para do liberalismo econômico.

7 Para uma discussão mais aprofundada, ver: Nancy Fraser, "Social Justice in the Age of identity Politics: Redistribution, Recognition, and Participation”, em Nancy Fraser e Axel Honneth (orgs.), Redistribution or Recognition? A Political-Philosophical Exchange, Londres, Verso, 2003.

8 Nota da redação francesa: O Family Wage, ou salário familiar, corresponde ao salário suficiente para alimentar e assumir uma família. Ele se integra ao modelo de um portador de renda, o homem chefe da família (breadwinner), que deve sustentar as necessidades de sua esposa no lar e de seus filhos. Integra o programa dos sindicatos na virada do século XIX, e de correntes maternalistas, ele fez objeto de reivindicações específicas demandar o aumento dos salários para que o assalariado pudesse assumir decentemente suas responsabilidades familiares. O salário familiar difere, então, do conceito francês de "salário maternal", que corresponde à eventual remuneração (pelo Estado) do trabalho doméstico (ao qual a alocação do salário único, no passado, se assemelha).

9 Por Estados “desenvolvimentistas" (developmental states), entendo serem os regimes pós-coloniais novamente independentes, que conduziram projetos específicos no sistema de Bretton Woods. Nos anos 1960 nos países em desenvolvimento, em particular na América Latina, esses projetos se concretizaram através de uma estratégia de controle de importações e de suporte às indústrias nacionais, por um financiamento fundado na apropriação nacional e estatal de excedentes, pela nacionalização de setores chave, por políticas de investimento em infraestrutura e pelo desenvolvimento das despesas públicas, notadamente em educação. Nos anos 1990, no entanto, o neoliberalismo colocou fim a essas políticas. Ao argumentar sobre a ameaça da dívida, o neoliberalismo impõe políticas de ajustamento estrutural que colocou fim à doutrina desenvolvimentista e constrangeu os Estado pós-coloniais a renunciar a seus benefícios, a abrir seus mercados e a diminuir gastos com suas despesas sociais.

\section{REFERÊNCIAS BIBLIOGRÁFICAS}

BOLTANSKI (L.) e CHIAPELLO (É), Le nouvel Esprit du capitalisme, Paris, Gallimard, 1999.

EINSENSTEIN (H.), “A Dangerous Liaison? Feminism and Corporate Globalization”, Science and Society, 69 (3), 2005, p. 487-518.

FRASER, (N.), "Women, Welfare and Politics of Need Interpretation" e "Struggle over needs: Outline of a Socialist-Feminist Critical Theory of late-Capitalist Political Culture", em Nancy Fraser (org.), Unruly Practices: Power, Discourse and Gender in Contemporary Social Theory, Minneapolis (Minn.) University of Minnesota Press, 1989. 
$\mathbf{6 3 4}$ : MERCANTILIZAÇÃO, PROTEÇÃO SOCIAL E EMANCIPAC̣ão

FRASER, (N.), “After the Family Wage: a Postindustrial Thought Experiment”, em Nancy Fraser (org.), Justice Interruptus: Critical Reflexions on the Postsocialist Condition, Londres, Routledge, 1997.

FRASER, (N.), 2003, "Social Justice in the Age of Identity Politics: Redistribution, Recognition and Participation”, em Nancy Fraser e Axel Honneth (orgs.), Redistribution or Recognition? A Political-Philosophical Exchange, Londres, Verso.

FRASER, (N.), 2005, Qu'est-ce que la justice sociale? Reconnaissance et redistribuition, édition établie et introduite par Estelle Ferrarese, paris, La Découverte.

FRASER, (N.), 2008, "Reframing Justice in a Globalizing World” em, Nancy Fraser, Scales of Justice: Reimagining Political Space in a Globalizing World, New York (N.Y.), Columbia University Press e Cambridge UK, Polity Press.

FRASER, (N.), "Feminism, Capitalism, and the Cunning of History”, New Left Review, 56, 2009, p. 97-117. FRASER, (N.) e GORDON (L.), “A Genealogy of 'Dependency': Tracing a Keyword of the US Welfare State”, em Nancy Fraser (org.), Justice Interruptus: Critical Reflexions on the Postsocialist Condition, Londres, Routledge, 1997.

MARX, (K.) e ENGELS (F.), Le Manifeste du Parti Communiste, 1848.

POLANYI, (K.), La Grande Transformation, Paris, Gallimard, 1983, (1ª ed., 1944).

RUGIE (J.G.), "International Regimes,

Transactions, and Change: Embedded Liberalism in the Postwar Economic Order", International Organization, 36, (2), 1982, p. 379-415.

Nancy Fraser

6 East 16 th Street, Suite 711 New York NY 10003 USA

fraserndearthlink.net
Henry A. \& LOUISE LOEB PROFESSOR OF Philosophy AND Politics - Chair, Politics Department, at New School for SOCIAL RESEARCH 